\title{
La influencia de Karl Rahner en la teología de Ignacio Ellacuría (II)
}

\author{
Martin Maier, \\ Centro de Reflexión Teológica, \\ San Salvador.
}

Proseguimos en este artículol la investigación de la influencia de la teología de Karl Rahner en la de Ignacio Ellacuría, teniendo en cuenta, sobre todo, las innovaciones teológicas de Rahner en el contexto del Concilio Vaticano II. En una primera parte analizaremos la teoría de Rahner sobre la evolución del dogma, la cual - tomando como punto de partida el discurso de Juan XXIII en la apertura del concilio- abrió nuevos horizontes. Con la teoría rahneriana, en efecto, están dadas las condiciones para comprender los signos de los tiempos como manifestaciones de la presencia y de la acción de Dios en la historia y en el mundo, a partir de lo cual Ellacuría llegará a hablar de una "historia de la revelación". En una segunda parte analizaremos el giro antropocéntrico de la teología rahneriana, cuyo fundamento teológico es una nueva concepción de la relación entre naturaleza y gracia, tal como la elabora en su doctrina sobre el existencial sobrenatural. Esta nueva concepción será determinante también para cọmprender la relación entre historia del mundo e historia de la salvación y la relación entre amor a Dios y amor al prójimo, todo lo cual asumirá y superará Ellacuría en su comprensión de la transcendencia histórica. Por último, en una tercera parte haremos una breve mención de la cristología de Rahner y su impacto en la de Ellacuría.

\section{Hacia una teología de los signos de los tiempos}

En la base de la renovación pastoral del Vaticano $\Pi$ estuvo presente una gran renovación teológica, y Karl Rahner fue uno de los teólogos que, antes y durante el concilio, introdujo importantes novedades teológicas. Lo fundamental de

1. La primera parte fue publicada en Revista Latimoamericana de Teología 39, 1996. pp. 233-255. 
esa novedad consistió en superar la teología neoescolástica que todavía predominaba en los esquemas preparatorios del concilio. Para esta teología neoescolática el punto de partida era el magisterio. Y su método, puramente deductivo, hacía uso de la Escritura, la doctrina de los Padres y la enseñanza de los teólogos solamente para justificar las tesis del magisterio. Por todo ello era una teología fundamentalmente ahistórica, a la defensiva y apologética.

En este transfondo fue fundamental la afirmación de Juan XXIII: Dios no se ha comunicado sólo en el pasado, sino que sigue manifestándose en el presente. Veamos en este apartado cómo Rahner ya había preparado teológicamente esta nueva visión, que será de importancia capital en el concilio, y cómo Ignacio Ellacuría la hizo fructífera en la teología de la liberación.

\subsection{Aires frescos: el discurso de apertura de Juan XXIII}

Los teólogos conservadores alrededor del cardenal Ottaviani habían preparado esquemas previos, que, en lo esencial, repetían simplemente la doctrina del magisterio. No esperaban nada nuevo del concilio y presuponían que éste terminaría pronto. Juan XXIII, sin embargo, ya en su discurso de inauguración escrito por él mismo de la primera hasta la última palabra - dió un gran viraje. Según Peter Hebblethwaite?, autor de la biografía hasta ahora más completa de Juan XXIII, el discurso vino a ser como la síntesis de su vida. Y para el teólogo alemán Elmar Klinger ${ }^{3}$ el discurso fue, a la vez, un programa para el concilio y una de sus claves hermenéuticas. Aquí nos limitaremos al Iratamiento que hace de la transmisión del depositum fidei.

Juan XXIII, después de disentir de los "profetas de calamidades", que "en los liempos modernos no ven otra cosa que prevaricación y ruina"4, aborda el tema de los diversos modos de transmisión de la doctrina sagrada, $y$, en nuestra opinión, abre así los caminos para un nuevo paradigma teológico. Claramente dirigido contra los grupos conservadores que querían que el concilio mantuviese simplemente las verdades del depositum fidei, dice el papa: "Nuestro deber no es sólo custodiar ese tesoro precioso, como si únicamente nos ocupasemos de la antigüedad, sino también dedicamos con voluntad diligente, sin temores, a la labor que exige nuestro tiempo, prosiguiendo el camino que la Iglesia recorre desde hace veinte siglos"s. Al hacer mención de "la labor que exige nuestro tiempo" el papa habla ya indirectamente de los signos de los tiempos, los cuales, en cuanto manifestaciones de la presencia de Dios en la historia actual, son de

2. Johannes XXIII. Das Leben des Angelo Roncalli, ZÜrich, 1986.

3. Armus: eine Herausforderung Gorres. Der Glaube des Konzils und die Befreiung des Menschen, Zürich, 1990.

4. Concilio Vaticano II. Constituciones. Decretos. Delaraciones, Madrid, 1965, p. 747.

5. Ibid., p. 749. 
importancia capital para poner la Iglesia a la altura de los tiempos (aggiornamento), interés fundamental de Juan XXIII al convocar el concilio.

De esta forma el Papa abrió un nuevo horizonte al concilio. Manteniendo siempre la fidelidad a la doctrina fundamental y a la Iradición de la Iglesia, Juan XXIII espera que en el concilio "se dé un paso adelante hacia una penetración docırinal y formación de las conciencias que esté en correspondencia más perfecta con la fidelidad a la auténtica docirina, estudiando ésı y poniéndola en conformidad con los métodos de la investigación y con la expresión literaria que exigen los métodos actuales"6.

Este es el núcleo teológico del discurso. El papa quiere que se dé un "balzo innanzi", un salto hacia adelante, como dice el texto original italiano7. Y para que no hubiera dudas, Juan XXIII afirma todavía más explícilamente: "Una cosa es el depósito mismo de la $\lceil e$, es decir las verdades que contiene nuestra venerada doctrina, y otra la manera como se expresa; y de ello ha de tenerse gran cuenta, con paciencia, si fuese necesario, ateniéndose a las normas y exigencias de un magisterio de carácter prevalentemente pastoral" 8 .

Este discurso de Juan XXIII fue recibido como un soplo de aire liresco. Abrió las puertas y las ventanas para poder descubrir en el mundo de hoy la presencia y las acciones de Dios. Invitaba también a los teólogos a estar atentos a los signos de los tiempos y a valorarlos sistemáticamente. El papa del concilio acababa así con una forma de deísmo de la revelación, según el cual Dios habría hablado sólo en el pasado, y la tarea de la Iglesia consistiría únicamente en custodiar el tesoro de la revelación. Esta intuición del Papa es lo que, tanto Rahner como Ellacuría, fundamentarán teológicamente al afirmar la posibilidad de una evolución del dogma y de una progresiva historia de la revclación en los signos de los tiempos.

\subsection{Rahner: la evolución del dogma}

El problema del depositum fidei y, especialmente, de los dogmas fue tratado por Rahner en un texto del año 1954 titulado "Sobre el problema de la cvolución del dogma"9. La tesis principal del artículo es que. de hecho, hay evolución en la explicitación dogmática de la fe. y Rahner menciona como ejemplo el dogma de la Asunción de Maria al cielo, proclamado el año 1950. Por un lado, este dogma es nuevo, pero, por otro lado, tiene que estar contenido ya, en cierta

6. Ibid.

7. Sobre las alteraciones que aparecieron en el texto oficial latino en comparación con el original italiano, $c f i$. L. Kaulimann/N. Klein, Johannes $X X I I I$. Prophetie im Vermachtnis, Fribourg/Brig, 1990. pp. 74s.

8. Concilio Vaticano II. p. 749.

9. En Escritos de Teologia 1, Madrid, 1961, pp. 51-92. 
forma, en el depositum fidei. Para mantener el equilibrio entre la novedad y la tradición Rahner alima que "la historia de la evolución del dogma es ella misma desvelamiento progresivo de su misterio"10, con lo cual afirma que también hay evolución en la fe y en la teología.

En cierta manera hay aquí una aplicación de la "lógica del conocimiento existencial" a la teología dogmática. Como vimos en la primera parte de este artículo, el presupuesto de la teología rahneriana de los ejercicios es que Dios puede comunicar su voluntad al ejercitante. Esta voluntad no se deja deducir ni de la revelación ya acontecida ni tampoco de principios éticos universales: Dios dice a un individuo algo nuevo e indeducible. De la misma manera, Rahner presupone en su tesis sobre la evolución del dogma que Dios puede comunicar a la Iglesia algo nuevo que todavía no ha sido dicho o reconocido como tal.

En otra línea de argumentación recalca Rahner que la intelección humana de la revelación está condicionada por el tiempo y la situación. En conceptualización más actual podríamos hablar de la contextualidad de todo discurso teológico, lo que también recalcará Ellacuría en sus "Tesis sobre posibilidad, necesidad y sentido de una teología latinoamericana". "La teología ha sido históricamente reflexión sobre la fe, pero desde una situación determinada social y culturalmente (aunque sin percatación refleja de los condicionamientos que esta situación imponía)"'II. Para Ellacuría esta rellexión situada y temporalizada conduce a un nuevo sentido de lo revelado. Al hablar de "una historia de los dogmas", Ellacuría parece referirse a Rahner, pero va más lejos y habla de "una historia de la revelación"12.

La idea de la evolución del dogma, tal como la plantea Rahner, y la de la historicidad de la revelación, tal como la plantea Ellacuría, presentan un prohlema difícil. Es doctrina de la Iglesia que la revelación "quedó concluida con la muerte del último apóstol" (DZ 2020s). ¿Cómo admitir, entonces, que puede haber manifestaciones de Dios también en el presente? Y si se Jan, ¿pueden cstas manilestaciones añadir algo a la revelación ya concluida o darle un nuevo sentido, como afirma Ellacuría?

Para comprender cómo una revelación que, por una parte, ha quedado concluida y que, por otra, puede dar de sí algo nuevo Ralıner concibe la revelación como "un diálogo hisıórico entre Dios y el hombre en el que acaece algo"1.3 - recordando que el "acaecer de la historia de la salvación ha alcanzado en

10. Ibid. p. 53.

11. "Tesis sobre posibilidad, necesidad y sentido de una teología latinoamericana", en A. Vargas-Machuca (ed.), Teología y mundo comiemporúneo: homenaje a Karl Rahuer, Madrid. 1975, Tesis 2.2.

12. Teologia políica, San Salvador, 1973. p. 74.

13. Sobre el problema.... p. 61. 
Cristo su punto máximo, incapaz de ser superado"14. Pero la "clausura" de la revelación es al mismo tiempo apertura "a la plenitud de Dios, ocultamente presente en Cristo"15. Según esto, para Rahner hay "una evolución progresiva del depósito originario de la fe bajo el influjo positivo de su luz donada a la Iglesia"16.

Para comprender cómo las proposiciones dogmáticas formuladas ulteriormente están contenidas en una forma anterior del saber consciente de la fe17. Rahner recurte al concepto de "explicación" de un conocimiento implícilo en otro explícito. Rahner cree que "también tales explicaciones de lo contenido sólo 'virtualmente' en las proposiciones inmediatas de la revelación pueden y deben ser llamadas 'revelación', y en cuanto tales, pueden ser enseñadas por la Iglesia como objeto de la específica fe divina"16. La explicitación de lo implícjto se hace, en esle caso, mediante operaciones lógicas bajo el apoyo y la luz del Espíritu divino. En otras palabras, "entre lo dicho formalmente y lo que, estando más allá, está, no obstante, reạlmente comunicado. (...) También lo virtualmente revelado puede ser creido y definido con fe divina" 19 . De esta forma puede darse un verdadero progreso de la revelación.

\subsection{Ellacuría: una historia de la revelación}

Ellacuría, por su parte, elabora una hermenéutica histórica de la palabra de Dios. Su presupuesto es que la palabra se actualiza en el acontecer histórico. Dicho de otra forma, la palabra de Dios "contiene posibilidades reales que sólo pueden actualizarse según las distintas necesidades nuevas del acontecer histórico"'20. A través de la realidad histórica la palabra de Dios va dando de sí lo que contiene realmente. En ese sentido la palabra de Dios es viva y creadora, y es capaz de decir cosas nuevas en situaciones históricamente nuevas. Y es que "si la re no consistiera más que en la aceplación por un hombre universal de un depósito dogmático fijo, la única acomodación consistiría en la correcta traducción de unos texios, de los que se ha olvidado previamente que tienen su lengua y su historia propias"2ı. Pero "la revelación misma es histórica en su misma estructura de modo que no puede tener un único sentido unívoco para situaciones realmente distintas" 22 .

\section{Ibid.}

15. Ibid., p. 62.

16. Ibid. p. 65.

17. Cfr: ibid., p. 69.

18. lbid., p. 77.

19. Ibid., p. 76.

20. Conversión de la Iglesia al reino de Dios para antunciarlo y realizasto en la hisioria, San Salvador. 1985. p. 266.

21. Teologia polírica..., p. 78.

22. "La teología como momento ideológico de la praxis eclesial", Estudios Eclesiasticos 207, 1978, p. 459. 
Para mantener, simultáneamente, la clausura y la apertura del depósito de la fe Ellacurfa recurre a Zubiri: "Se puede admitir que el depósito de la fe está concluso, pero como muy bien ha notado Zubiri esı́a concluso como sistema de posibilidades; ahora bien la historia es precisamente la actualización de posibilidades"23. El depósito de la revelación, como sistema cerrado de posibilidades, va a dar de sí todo lo que contiene en su realización histórica24.

\subsection{Una teología de los signos de los tiempos}

Elemento clave en este diálogo hermenéutico entre revelación e historia son los signos de los tiempos. Como hemos visto, Juan XXIII tuvo la fe y la confianza de que Dios habla hoy también a los hombres en los acontecimientos históricos. Nuestra tesis es que la teología realiza el "salto hacia adelante" que exigió Juan XXIII en su discurso de apertura precisamente en la integración sistemática de los signos de los tiempos en su quehacer. Queremos mostrar, además, que la teología de la liberación es la que tomó y sigue tomando especialmente en serio los signos de los tiempos. En este sentido, la teología de la liberación es también la teología que ha sacado las consecuencias más profundas del concilio por lo que toca a la nueva postura de la Iglesia frente al mundo y a la nueva relación entre fe e historia25.

Los dos enunciados más importantes del concilio sobre los signos de los tiempos se encuentran en la constitución pastoral sobre la Iglesia en el mundo aclual, la Gaudium et Spes. El número 4 afirma que "la Iglesia debe escrutar a fondo los signos de la época e interpretarlos a la luz del evangelio, de forma que, acomodándose a cada generación, pueda la Iglesia responder a los perennes interrogantes de la humanidad sobre el sentido de la vida presente y futura y sobre la mutua relación de ambas cosas. Es necesario, por ello, conocer y comprender el mundo en que vivimos, sus esperanzas, sus aspiraciones y el sesgo drámatico que con frecuencia lo caracteriza". Con Jon Sobrino vamos a llamar a esta comprensión de los signos de los tiempos histórico-pastoral26.

Pero la Gaudium et Spes ofrece otro significado leológicamente más profundo de los signos de los tiempos en el número 11: “El pueblo de Dios... procura discernir en los acontecimientos, exigencias y deseos, de los cuales participa juntamente con sus contemporáneos, los signos verdaderos de la presencia o de los planes de Dios". La historia es vista aquf en una dimensión sacramental, en

23. Teología políica... p. 7.

24. Cfr. Conversión de lo Iglesia..., p. 234.

25. Esto lo hemos desarrollado más ampliamente en nuestro artículo "Teología de la liberación en Latinoamérica", Razón y Fe 236, 1997, pp. 281-296.

26. Cfr. J. Sobrino. "Los "signos de los tiempos" en la teologia de la liberación", en J. M. Lera (ed.). Fides quae per carisatem operatur. Homenaje al P. Juan Alfaro S.J. en su. 75 años, Bilbao, 1989, pp. 249-269. 
su capacidad de manilestar a Dios en el presente. De nuevo con Sobrino llamamos a esta acepción de los signos de los tiempos histórico-teologal.

Lo novedoso de la acepción teologal de los signos de los ticmpos en la teología de la liberación es que se toman en scrio como lugar teológico. Dice Ellacuría: "En los tan traídos y llevados signos de los ticmpos acontcce la revelación de Dios en la historia"27. Escrular los signos de los tiempos signilica. entonces, poner en relación la revelación de Dios con la historia real. Al hacerlo, la tcología no descarla la Escritura como luente más importante de lodo conocimiento tcológico y tampoco menosprecia la tradición y el magisterio eclesial. Pero sí intenta poner en relación los signos de los licmpos con el depositum fidei, ponerlos en diálogo, interpretar los signos de los ticmpos a la luz de la Escritura.

Este concepto de signos de los tiempos en su acepción histórico-teologal presupone la unidad de la historia, como analizaremos más adelante: no hay separación entre historia profana e historia sagrada, sino que la primcra es mediación de la segunda. A eso corresponde también la interacción de la historia de la salvación y de la salvación de la historia, como lo recalca axiomáticamente lgnacio Ellacuría: "Los 'signos de los tiempos' son lambién comprobación de esta necesaria relerencia a la historia, cuando se quiere descubrir la presencia histórica de Dios entre los hombres; los signos de los tiempos percibidos son una de las mediaciones indispensables para entender y hacer la novedad de la historia de la salvación"28.

En este contexto Ellacuría introduce una distinción fundamental entre lugar y luentes de la tcología. Las fuentes corresponderían al depositum fidei, y el lugar sería el Jesde dónde se hace leología. Ellacuría describe la interacción de ambos de la manera siguiente: "La distinción no es estricla ni, menos aún, excluyente. porque de algún modo el lugar es luente en cuanto que aquél hace que ésta dé de sí esto o lo otro, de modo que, gracias al lugar y en vittud de él, se aclualizan y se hacen realmente presentes unos determinados contenidos"29. En otras palabras, lo que las mismas fuentes dan de sí depende del lugar. Y como lugar más propicio para "leer" las luentes Ellacuría proponc - desde la perspectiva específcamente latinoamericana- el mundo de los pobres. En ese sentido la opción por los pobres tiene también una fundamental lunción hermenéutica 10.

27. Conversión de la lglesia.... p. 233.

28. "Fe y justicia", en Varios. Fe, justicia y opción por los oprimides. Bilbao. 1980, p. 24.

29. Compersion de la lglesia..., p. 268.

30. Cfr. lambién J. L. Segundo. "La opción por los pobres como clave hermenéutica para entender el Evangelio". Sal Terrae 74. 1986, pp. 473-482. 
La categoría de los signos de los tiempos fue asumida en su densidad teologal por Medellín. Los obispos latinoamericanos allí reunidos reconocicron como el signo de los tiempos más importante para Atnérica Latina la irrupción de los pobres. Para Ellacuría los pobres son signos de la presencia de Dios y continuación histórica del Cristo crucificado. Los designa como el signo de los tiempos: "Ese signo es siempre el pueblo históricamente crucificado, que junta a su permanencia la siempre distinta forma histórica de crucifixión"3.

Jon Sobrino ha resumido la importancia fundamental de los signos de los tiempos para la teología de la manera siguiente: "Al nombrar esos signos de los tiempos - la injusta y colectiva miseria que clama al cielo y los anhelos de liberación- (Medellín) apuntó a aquel lugar histórico y tcológico desde el que se debe hacer teología y desde el que se debe integrar todo lo que la teología elabora a partir de sus tuentes, revelación, tradición y magisterio: el mundo de los pobres" 32 .

\section{La unidad de naturaleza y de gracia}

La relación entre naluraleza y gracia es un problema fundamental para la tcología, muy debatido en los años anteriores al concilio y es determinante en el enfoque de muchos otros problemas, tales como: la relación entre la liberlad de Dios y la libertad del hombre, entre historia del mundo e historia de la salvación. entre razón y fe, entre filosoff́a y teología, entre reino de Dios y mundo. En este upartado vamos a analizar la contribución de Rahner a superar el extrinsecismo de la gracia divina con relación a la naturaleza humana y la de Ellacuría a superar el extrinsecismo con relación a la historia.

\subsection{Rahner: el existencial sobrenatural}

Rahner hizo una importante contribución a la lámosa controversia sobre naluraleza y gracia que se desarrolló en los años 50 . Henri de Lubac resumió entonces la cuestión de fondo de la siguiente manera. "Somos criaturas y veremos a Dios. El deseo de verle está en nosotros, pero solamente será cumplido por un puro don"33. Rahner, en su método transcendental, se pregunta por las condiciones de posibilidad en el ser humano para recibir ese don gratuito de la gracia divina. Como vimos en el apartado sobre su filosofía, el hombre en cuanto espíritu está abierto al horizonte infinito del ser. Ahora bien, teológicamente hablando. esta apertura a la Iranscendencia es la capacidad fundamental del hombre para recibir una posible autocomunicación de Dios. A esta capacidad es

31. "Discernir el signo de los tiempos", Diakonia 18, 1981, p. 58.

32. "La teología en América Latina", en Iniciación en la práctica de la teologia. IIIroducción, Madrid. 1984, p. 368.

33. "Le mystère du surnaturel", Recherches de Science Religieuse 36. 1949. p. 11. 
a lo que Rahner la llama potentia oboedientialis: "La náturaleza abierta del hombre es, por razón de su transcendencia (potencia obediencial), un posible destinatario de la autocomunicación libre del mismo Dios en la gracia y en la visón de Dios intuitiva"34.

\subsubsection{Superación del extrinsecismo de la gracia}

La potentia oboedientialis, en cuanto posibilidad en el hombre de recibir una eventual autocomunicación divina, preserva la dimensión de la liberlad en el acontecimiento de la relevación. Dios se comunica libremente al hornbre, y el hombre recibe libremente la gracia divina. El acontecimiento de lá revelación es el encuentro de la libertad humana y la libertad divina. Pero hemos recalcado también que, en la teología de Rahner, la autocomunicación de Dios ya acaecida es un presupuesto fundamental, tanto a nivel existencial cono metodológico. AsI de hecho, la potentia oboedientialis ya está siempre actualizada. Esta actualización de la potentia oboedientialis es lo que Rahner dcsigna con su famoso concepto de "existencial sobrenatural".

En su Diccionario teológico, escrito juntamente con Herbert Vorgrimler en 1961, Rahner describe así los presupuestos ontológicos del existencial sobrenatural. "Este concepto está basado ontológicamente en las siguientes proposiciones: el hombre, previamente a la justificación por la recepción sacramental o extrasacramental de la gracia, se encuentra incluido en la voluntad salvífica universal de Dios; el hombre se encuentra ya siempre como redimido y absolutamente obligado al fin sobrenatural. Esta situación es ya determinación ontológico-real del hombre que adviene gratuitamente a su naluraleza y, por tanto, es sobrenalural, aunque nunca falte de hecho en el orden real" 35 .

En un texto de 1950, "Sobre la relación entre la naturaleza y la gracia", Rahner intervino directamente en el debate sobre naturaleza y gracia, que habían comenzado los representantes más destacados de la "nouvelle théologic" en Francia. Rahner toma como punto de partida la crítica que la nouvelle théologie había hecho a la doctrina escolástica "de que la gracia aparece como un mero añadido o segundo piso, muy bello en sí, que Dios, por su libre disposición, coloca sobre la naturaleza" 36 .

Esta doctrina propone un extrinsecismo de la gracia divina, y para superarlo Rahner introduce su idea del "existencial sobrenatural": la ordenación del hombre en lo más profundo de su existencia hacia la autocomunicación de Dios como puro don de su gracia. La esencia de la gracia es, entonces. para Rahner la

34. K. Rahner y H. Vorgrimler, Diccionario Tesológico. Barcelona, 1970. p. 475.

35. Ibid., p. 245.

36. "Sobre la relación entre la naturaleza y la gracia". en Escritos de Teología $I$. Madrid, 1963, p. 326. 
autocomunicación de Dios en el amor. Pues bien, esa autocomunicación amorosa de Dios ya ha acaecido. Lo que hace Rahner con su método transcendental es preguntarse por las condiciones de posibilidad en el hombre para recibir esta aulocomunicación de Dios. La conclusión es que "esta capacidad para el Dios del amor personal, que se entrega a sí mismo, es el existencial central y permanente del hombre en su realidad concrela" 37 . En otras palabras, la gracia no es sino la radicalización de la esencia del hombre y no constituye un piso adicional que se superponga a la naturaleza humana. Así, la naluraleza pura en sentido estricto no existe porque siempre está ya transformada por la gracia divina. Por eso Rahner dice que la naturaleza, en sentido teológico y como contra-conceplo de lo sobrenatural, es conceplualmente un "resto"38. Lo mismo vale para la potentia oboedientialis que, de hecho, siempre está elevada a existencial sobrenatural.

En síntesis, podemos decir que el existencial sobrenatural es un libre don de la gracia divina, pero, de hecho, es un elemento constitutivo y ontológico de la existencia humana, y así siempre está dado bajo la forma de la oferta de una autocomunicación de Dios. De esta forma Rahner puede mantener el equilibrio entre el deseo en nosotros de ver a Dios y la pura gratuidad de la autocomunicación divina.

\subsubsection{Antropocentrismo y teocentrismo}

El existencial sobrenatural está también en el centro de la antropología teológica de Rahner. El ser humano para Rahner es el acontecimiento de la absoluta e indulgente autocomunicación de Dios. "La esencia y el sentido de la autocomunicación de Dios al sujeto espiritual así entendida consisten en el contacto inmediato de Dios con el sujeto espiritual, es decir, en la unión básica del conocer y el amar. La autocomunicación entitativa ha de interpretarse de antemano como condición de posibilidad del conocimiento y del amor personal inmediato a Dios"39. En esta perspectiva antropológica aparece el existencial sobrenatural como la posibilidad en cada hombre de hacer una experiencia de Dios: "el hombre como el existente que siempre y en todas partes se halla dotado - al menos bajo la modalidad de oferla- de la autocomunicación de Dios, y, por eso, experimenta el acontecimiento fundamental de lo que. en terminologla cristiana, recibe el nombre de revelación"40.

En la historia de la teología moderna Rahner es quizás el teólogo más importante de lo que se ha llamado el cambio o el giro antropocéntrico. Así, Johann

37. Kid., p. 34I.

38. Cfr. ibid., p. 342.

39. “Antropología y teología", en Fe cristiana y sociedad modernn XXIV, Madrid. 1987. p. 46.

40. Ibid., p. 63. 
B. Metz ha caracterizado con acierto la teología de Rahner como teología antropológica, lo que confirma el mismo Rahner. " ¿Cómo puede un cristiano hablar adecuadamente de Dios, si no habla al mismo tiempo del hombre? La palabra hecha carne es y sigue siendo el hombre eterno e ilimitado. No se puede conocer a Dios tal como es si no se piensa al mismo tiempo en él como el Dios que creó al hombre. Por consiguiente, no se dispone de una teología completa si no se tienen presentes sus aspectos antropológicos. Si se quiere hablar con acierto de Dios, es preciso hablar del hombre" 4 .

Pero al mismo tiempo Rahner siempre se preocupó por un recto equilibrio entre antropocentrismo y teocentrismo. "El cristianismo se considera como un mensaje sobre la salvación del hombre. Culmina en que Dios, tal como es con su soheranía y su gloria absolutas, puede ser el contenido y el centro de la existencia humana y quiere serlo de hecho por pura gracia; por tanto, no nos hallamos ante un Dios que 'de suyo' no nos afecta en absoluto; el 'teocentrismo' - rectamente entendido- se transforma, pues, en un 'antropocentrismo'. Y a la inversa, según la enseñanza cristiana, el hombre sólo puede encontrarse a sí mismo cuando se abandona a la libre incomprensibilidad de Dios orando y amando, y, así, transforma él mismo su 'antropocentrismo' en 'teocentrismo'"42.

Resumiendo, podernos decir que Rahner supera todo dualismo y extrinsecismo entre naturaleza y gracia. La gracia determina la naturaleza humana en su esencia y la ordena internamente a la visión de Dios en Cristo. La compenetración de naturaleza y gracia corresponde tanto a la compenetración de filosofía y teología como a la de teología y antropología, historia de la salvación e historia del mundo, amor a Dios y amor al prójimo.

\subsubsection{Historia del mundo e historia de la salvación}

Rahner transpone la idea del existencial sobrenatural también al plano de la historia en el sentido que la historia ya está siempre transida de la gracia divina y orientada hacia la salvación, de tal manera que no hay una historia puramente natural, profana, sino una unidad diferenciada entre historia de la salvación e historia del mundo. Eso lo explica en tres tesis en su texto "Historia del mundo c historia de la salvación", publicado en el año 1962 ( $y$, por cierto, es éste otro de los pocos textos de Rahner que aparecen explícitamente citados en los escrilos teológicos de Ignacio Ellacuría). Reproducimos textualmente el resumen muy denso y acertado que hace Ellacuría de las tesis de Rahner en su escrito "Hisloricidad de la salvación cristiana":

1) la historia de la salvación acaece y se compenetra con la historia del mundo, porque la salvación acaece ahora, es aceptada libremente por el hom-

41. P. Imhof y H. Biallowons, Karl Rahner in Gespräch I, München, 1982, p. 40.

42. "Antropología...", p. 17. 
bre y permanece escondida en la historia profana en la dualidad de su posibilidad de salvación y de condenación; 2) la historia de la salvación es distinta de la historia profana, ya que la historia profana no permite dar una interpretación unívoca respecto de la salvación y de la condenación, aunque ha de hablarse de una constante interferencia y coexistencia entre la historia profana y la historia de la salvación y de la revelación, no obstante que Dios por su palabra, que es un elemento constitulivo de la historia de la salvación, ha segregado una parle de la historia para constituir esa parte como la historia de la salvación expresa, oficial y propia; 3) la historia de la salvación explica la historia profana en cuanto desmitologiza y desnuminiza, en cuanto la ve como antagónica y oscurecida, en cuanto la interprcta como existencialmente despotenciada y en cuanto la explica cristocéntricamente. En última instancia, la historia prolana es la condición de posibilidad de la historia de Cristo que es también la historia de Dios semejantemente a como la historia natural en su materialidad y vitalidad es la condición de posibilidad del surgimiento del espíritu finito 4 .?.

Ellacuría no entra aquí a discutir la concepción de Rahner, algo desunificada todavía por lo que toca a la relación entre la historia del mundo y la historia de la salvación, aunque sí alude a que las tesis de Rahner en este ensayo pertenecen a un período de su pensamiento menos interesado en la proyección política. Pero este resumen de la posición de Rahner —como lambién el de la de Pannenherg - a propósito de la revelación en su relación con la historia le sirve para presentar el problema al cual Ellacuría va a dar su propia solución. Veámoslo.

\subsection{Ellacuría: de la naturaleza a la transcendencia histórica}

lgnacio Ellacuría, por razones de edad, no pudo intervenir en la controversia sobre naturaleza y gracia de los años 50 . Sin embargo la problemálica de l'ondo esıá muy presente cn varios de sus escritos. De nuevo, Ellacuría tomará como punto de partida la concepción rahneriana, pero superándola por medio de una adecuada historización.

\subsubsection{Historización del existencial sobrenatural}

En sus "Tesis sobre la posibilidad, necesidad y sentido de una tcología latinoamericana", dedicadas a Karl Rahner, Ellacuría, aun sin mencionarlo explícitamente, acepta plenamente el existencial sobrcnalural como disposición interna Jel hombre para recibir la autocomunicación de Dios: "La tcsis clásica de que la plenitud del hombre concreto requiere históricamente la comunicación de Dios y

43. "Historicidad de la salvación cristiana". Revista Lainomericana de Teologia I (1984) p. 26. 
que la plenitud de la comunicación de Dios lleva a la plenitud del hombre histórico es una hipotésis basica de la teología latinoamericana"44.

Sin embargo, en la matización de esta lesis Ellacuría va más lejos que Rahner: solamente en la experiencia histórica del cristianismo se sabe cuál es la plenitud del hombre y la plenitud de Dios, que no es una plentitud idealista y ahist6rica. Estas plenitudes "pasan" por la lucha y por la muerte y llevan de la opresión a la liberación. Asimismo Ellacuría insiste en la dimensión social e histórica del acontecimiento de la autodonación de Dios - dimensiones no suficientemente presentes en el pensamiento de Rahner45.

En su texto "Historia de la salvación" Ellacuría hace suyo explicitamente la doctrina rahneriana del existencial sobrenatural pero, de nuevo, integrándola en el contexto de su teología de la historia. Toma como punto de partida no la apertura del sujeto hacia una posible autocomunicación divina, sino la apertura transcendental de la historia que "engloba en sí la apertura de la realidad y la doble apertura unificada de la inteligencia y de la voluntad, de la aprehensión y de la opción"46. Sigue entonces la frase en que Ellacuría menciona a Rahner. "Esta apertura que en cada hombre es la apertura transcendental clevada de un 'existencial sobrenatural' (Rahner), es en la tolalidad de la historia la apertura transcendental elevada de una historicidad gratuita."

Ellacuría traspone, pues, al nivel de la realidad histórica lo que para Rahner es el existencial sobrenatural al nivel de la subjetividad humana. Así transciende el subjetivismo transcendental de Rahner en la dirección de la objetividad y de la realidad de lo histórico. En forma análoga a como el espíritu humano está abierto a la revelación gratuita de Dios, así la historia está abierta a su elevación gratuita a Dios. Del mismo modo supera el extrinsecismo en la concepción de la elevación salvífica de la historia a Dios. "La historia es de suyo transcendentalmente abierta y en esa transcendentalidad está ya la presencia, al menos incoada, de Dios"4?.

\subsubsection{Crítica al planteamiento natural-sobrenatural}

Ellacuría sitúa la discusión naturaleza y gracia en el campo de la historia, y -en ello- critica también el planteamiento de lo natural y lo sobrenatural como tal. Así comienza su libro Teología política: "durante siglos y debido a una mentalidad filosófica griega, ajena a la orientación bíblica, ha sido el tema lundainental el de la rclación de lo sobrenatural con lo natural"48. Eso ha tenido

44. Tesis 9.6 .

45. En este sentido Johann B. Metz critica a su maestro Rahner. Cfr. La fe en la historia y la sociedad, Madrid, 1979. pp. 164-177.

46. "Historia de la salvación", Revisıa Latinoamericana de Teología 28. 1993. p. 8.

47. Ibid.

48. Teología política. p. I. 
consecuencias negativas tanto para la teología como para la praxis cristiana: se diluyó la historicidad en favor de una esencialidad estática debido al peso de la filosofía platónica y aristotélica49. Este modo de pensar estaba configurado por las calegorías de materia y forma, de sustancia y accidentes, lo cual llevó a una oposición entre la naturaleza, como lo permanente e inmovible, y la historia, como lo no permanente ni repelible. En este marco filosófico Dios aparece como el ser absoluto e inmovible que no puede tener una historia. Las consecuencias para la antropología son las siguientes:

Se ve al hombre como parte del cosmos, como ente natural, sólo que con una naturaleza más elevada, o, si se prefiere, con una pertenencia a la naturaleza más libre. El ser es la naturaleza y la naturaleza es el ser idéntico a sí mismo a pesar de sus accidentales y transitorias mutaciones. En el fondo no ocurre nada, y si algo ocurre es siempre lo mismo. Se comete así una doble reducción: interpretación estática de la naturaleza, e interpretación naturalista del hombreso.

Ellacuría se opone a una interpretación naluralista-sustancialista del ser humano y de las realidades sociales, pues eso "Hleva a hacer extrínsecus entre sí al hombre y a Dios y a negar el decurso de Dios en el hombre precisamente en la historia y no en la naturaleza, si no es de un modo muy parcial"sI. Por ello sugiere, positivamente, plantear el problema en términos de historia que engloba y transciende el de naturaleza: "La historia de la salvación expresaría mucho más biblica y cristianamente lo que los clásicos llamaban sobrenaturaleza, la salvación en la historia expresa mucho más 'actualmente' lo que aquellos mismos clásicos recubrian con el término 'naturaleza"'52. El esquema montado sobre la dualidad natural-sobrenatural es superado por el esquerna teológico monlado sobre historia de la salvación-salvación en la historia5.?, planteamiento mucho más conforme a la idea y experiencia de Dios del pueblo de Israel y de la Biblia: "Es en la biogralía personal y la historia de los pueblos donde se ha hecho realmente presente Dios sin que esto excluya transformaciones ónticas"s4. En otras palabras, la revelación acaece más en la historia que en la naturaleza: "No la naturaleza y el orden natural, sino más bien la hisloria y la ordenación social son, por lo pronto, el cuerpo mediador de Dios" 55.

Ellacuría supera. pues, una concepción naturalista de la realidad a través de una concepción histórica, una concepción individualista del hombre a través de

49. Cf: "Historia de la salvación"... p. 3.

50. Teología políticu. p. 1.

5i. Ibid.. p. 6.

52. Ibid.. p. 1 .

53. Cfr. Conversión de la iglesia..., p. 223.

54. "Historia de la salvación". p. 5.

55. Comversión de la iglesia.... p. 225. 
una concepción socio-histórica. La dimensión de lo humano histórico engloba la dimensión natural y la dimensión individual:

El mundo concretamente real es el mundo histórico, donde el sujeto de esa historia es la sociedad y el objeto de ella el proceso socio-político entero. Hay un claro sobrepasamiento de posiciones subjetivistas hacia la objetividad y realidad de lo histórico. Frente a la coseidad objetiva del mundo natural se afirma la especifidad de lo humano, pero frente a la subjetividad de lo humano-individual se afirma lo humano-histórico. Esta dimensión de lo humano-histórico engloba la dimensión natural y la dimensión individual. No es idealista-subjetivista, pero tampoco materialista-colectivista.56.

Este enfasis en la dimension histórica de la le y de la salvación cristiana tiene también consecuencias importantes para la concepción de la teología. Si antes la teología era "un puro saber teórico sobre realidades no cambiables y, por tanto, poco tendría que ver con la historia"57, ahora es entendida en su contextualidad y densidad histórica.

\subsubsection{La unidad de la historia}

La elaboración sistemática más importante sobre teología de la historia la hizo Ellacuría en su texto "Historicidad de la salvación cristiana" en 1984. La tesis fundamental del articulo es que no hay dos historias: una historia de Dios y una historia de los hombres, una historia sagrada y una historia profana, sino que hay una sola historia de salvación. Como ya hemos dicho, en este texto aparece el ya citado resumen del texto de Rahner "Weltgeschichte und Heilsgeschichte" (al parecer, Ellacuría usó en su rcsumen el texto original en alemán).

Ya hemos dicho que, en general, Ellacuría sustituye el esquema teológico montado sobre la dualidad natural-sobrenalural por el esquema teológico montado sobre historia de la salvación-salvación en la historia. E insiste también, más que Rahner, en la unidad de la historia: no se dan dos historias, una historia profana y olra sagrada, una historia de los hombres y otra de Dios, sino que se da una sola historia de salvación. Así como para Rahner, a nivel personal, la naturaleza pura es conceptualmente un "resto" porque está siempre elevada por la gracia divina a existencial sobrenatural, así para Ellacuría no hay historia pura del mundo. porque en ella siempre está acluando la salvación divina. En este contexto Ellacuría critica un falso concepto de transcendencia, entendida como aquella realidad que estuviera fuera o más allá de lo que se aprehende inmediatamente como real. Propone otro modo de entender la transcendencia "como algo que transciende 'en' y no como algo que transciende 'de', como algo que

56. Tesis 9.3.2.1.

57. "La teología como momento ideológico...", p. 458. 
impulsa físicamente a 'más', pero no sacando 'fuera de'; como algo que lanza pero que al mismo tiempo retiene" 58 . Ellacuría radicaliza, pues, la compenetración de transcendencia e historia de Rahner: "La transccndencia (...) se presenta como histórica y la historia se presenta a su vez como transcendente por más que resulte difícil encontrar los conceptos adecuados para mantener esta indivisa unidad sin confusión" 59 . Al final de la cila ya se vislumbra que la clave para pensar esta unidad diferenciada entre transcendencia e historia es el dogma cristológico de Calcedonia, de lo que trataremos más en adelante.

Ellacuría niega, pues, toda dualidad de la historia en el sentido de que hubiera una historia prolana, supuestamente puramente natural, y una historia sagrada, supuestamente puramente sobrenatural: "No hay sino una sola historia que brola de la voluntad amorosa y salvífica del único Dios verdadero, del Dios trinitario como verdadero Dios, por lo que la separación real entre una historia profana y una historia de la salvación debe ser abolida, no obstante las múltiples distinciones que deben hacerse dentro de la misma historia de la revelación y de la salvación"60. La historia es a la vez el lugar de la realización del hombre y de la realización y revelación de lo absoluto. "Es en lo histórico donde convergen el polo de lo divino y el polo de lo humano, donde se da el encuentro del hombre con Dios"61.

Hay que recalcar, sin embargo, que no se trata de una simple identilicación entre Dios e historia, sino de una clevación de la historia a Dios. La historia se convierte, entonces, en historia de salvación sin necesidad de ninguna intervención extrínseca de Dios. Entre una concepción monista y una concepción dualista Ellacuría concihe la historia como una unidad estructural "en la que la diversidad cualitativa de los elementos es absorbida cn la unidad estructural de su realidad profunda. Desde una concepción estructural puede salvarse, sin separación, la unidad de la historia y la diversidad de sus distintos elementos"62.

Como resumen podemos decir que Ellacuría supera una concepción naturalista de la realidad y una concepción individualista del hombre, avanzando hacia una concepción histórica de la realidad y avanzando hacia una concepción humano-histórica y social. No se trala, sin embargo, de una mera negación, sino de una elevación en el sentido hegeliano de Aufheburg: la dimensión de lo humano-histórico y social engloba la dimensión nalural y la dimensión individual63. "Puede decirse que la historia engloba y supera tanto el ámbito de lo

58. "Historicidad de la salvación...". p. 18.

59. Mid.. p. 9.

(0). Ibid. p. 21 .

61. Tesis 9.3.1.

62. "Historia de la salvación". p. 21.

6.3. Cfr. Tesis 9.3.2.1. 
natural como el ámbito de lo subjetivo y personal, y en ese sentido, lejos de excluirlos, los enmarca y polencia"64. Así supera Ellacuria la concepción individualista-personalista e idealista-transcendental de Rahner.

\subsubsection{El planteamiento pecado-gracia}

Otra manera de concebir la relación entre lo natural y lo sobrenatural es, según Ellacuría, pensar la relación entre pecado y gracia: "La diferencia fundamental no es entre naturaleza y sobrenaturaleza, una vez entrados en la única historia de Dios que en la misma creación del hombre lo ha elevado a participar personalmente de su propia vida divina, sino entre pecado y gracia"65. Ellacuría integra sistemáticamente este planteamiento en su teología de la historia en el sentido de que ésta es "el lugar por antonomasia de la revelación y glorificación de Dios y es también lugar de ocultamiento y de perdición"66. Aunque Ellacuría recalca con vigor la interrelación entre historia y salvación eso no significa que pasa por alto la realidad del pecado. La única historia de salvación aparece como historia de gracia e historia de pecado67. Acciones que atentan contra la vida son del reino del pecado, y acciones que propician la vida son del reino de la gracia.

De esta unidad de la historia como historia de pecado e historia de gracia surgen algunas cuestiones fundamentales para la praxis cristiana. “¿Qué tienen que ver los esfuerzos humanos por una liberación hisıórica, incluso socio-política, con la instauración del reino de Dios que predicó Jesús? ¿Qué tiene que ver el anuncio del reino de Dios y su realización con la liberación histórica de las mayorías oprimidas?"68. Dicho en otras palabras, la praxis cristiana tiene que contribuir a un cambio de la historia en términos de justicia y de liberación. Y aquí Ellacuría —esla vez explícilamente - adopla otra intuición importante de Rahner: "En definitiva, quien trabaja intramundanamente por el futuro nuevo de la historia, si vive de la promesa y de la esperanza cristiana, trabaja por la aparición definiliva de Dios como futuro absoluto del hoinbre (Rahner)"69, aunque más adelante señala en qué sentido la idea rahneriana de Dios como futuro absoluto del hombre tiene que ser superada: Dios no solamente debe ser afirmado como absoluto de la experiencia individual, sino también como absoluto de la experiencia histórica: "lo invisible de Dios puede ser reconocido por el curso de la historia"7o.

64. “Historicidad de la salvación...", p. 13.

65. Ibid., p. 30.

66. "Historia de la salvación". p. 12

67. Cfr. ibid., p. 22.

68. "Historicidad de la salvación...", p. 7.

69. Conversión de la iglesia.... p. 245.

70. lbid. 
Ellacuría no identifica, simplemente, historia y salvación, y mantiene la reserva escatológica: "la liberación cristiana es, a la par, salvación en la historia y más allá de la historia. (...) La historia y el más allá de la historia no se identifican, pero mutuamente se potencian"7I. Igualmente, la evangelización no agota su plenitud en la dimensión política: "es obvio que el mensaje revelado, aun aceptando que siempre ha de presentarse en términos de salvación histórica, trasciende realmente la salvación histórica, que ya es en sí misma algo que trasciende el planteamiento estructuralmente político"72.

Para unificar adecuadamente lo histórico-político y lo trascendente-salvílico Ellacuría remitía a Monseñor Oscar Romero. Así dice de él que "nunca se cansó de repetir que los procesos políticos (...) no bastan para traer a los hombres la liberación integral"73. Monseñor insistía en la transcendencia como un "Inás" que la historia y que lo puramente humano, pero se trataba de "una transcendencia que nunca se presentaba como abandono de lo humano, como huída del hombre, sino como su superación y perfeccionamiento. Un más allá que no abandona el más acá, sino que lo abría y lo impulsaba hacia adelante"74. En conclusión, para Ellacuría Monseñor Romero sabía mantener perfectamente en su compromiso el equilibrio entre lo histórico y lo transcendente: "De múltiples formas puede mostrarse esta unidad indivisa entre la dimensión histórica y la dimensión transcendente de su compromiso cristiano, de la liberación que él anunciaba: la presencia del Dios de vida y libertad lo impulsaba a comprometerse con la historia de su pueblo y la historia de su pueblo quería él elevarla hasta los desiginios de Dios"75.

\subsection{El amor a Dios y el amor al prójimo}

Otra consecuencia de la comprensión rahneniana de la rclación entre naturaleza y gracia es una nueva explicación de la unidad del amor a Dios y amor al prójimo, y Ellacuría concretizará e historizará la unidad del amor a Dios y al prójimo en la opción por los pobres y en la lucha por la justicia. En este sentido, el texto bíblico que aparece con más frecuencia en la obra de Rahner y lambién en la teología de la liberación es el pasaje del juicio final según san Matco (Mt $25,31-45$ ). La identificación de Jesús con los pobres, los necesitados y los marginados es la clave cristológica de la unidad del amor a Dios y al prójimo.

71. Ibid., p. 245 .

72. Ibid., p. 274.

73. "Monseñor Romero, un enviado de Dios para salvar a su pueblo". Revista Latinoamericana de Teología 19,1990, p. 9.

74. Ibid.

75. "La UCA ante el doctorado concedido a Monseñor Romero", ECA 437, 1985, p. 170. 
Rahner trata el tema sistemáticamente en un texto titulado "Sobre la unidad del amor a Dios y del amor al prójimo"76.

\subsubsection{Rahner: la unidad del amor a Dios y al prójimo}

Rahner alimma que en esta unidad no se diluye el amor al prójimo en las profundiades del amor a Dios sino que "se trata más bien de comprender que una magnitud no se da sin la otra, que una sin otra no pueden ser entendidas ni realizadas, que a lo que propiamente es lo mismo hay que darle dos nombres para conjurar así su misterio, uno e irrepremible" 77 . Tras unas reflexiones sobre el amor activo, como lugar de la iluminación existencial del hombre moderno, Rahner analiza las afimnaciones de la Escritura sobre el amor al prójimo y el amor a Dios. Este recurso amplio y extenso a la Biblia en el tratamiento de una cuestión sistemática no es normal en Rahner, aunque tampoco la Escritura le ofrece total claridad sobre la cuestión de si se trata de un único mandamiento o de dos mandamientos distintos.

Rahner parte de la reflexión teológica, que desemboca en la siguiente tesis: "un auténtico amor al hombre alcanza su propia esencia y su hondura moral absoluta, es elevado y emprendido por la gracia divina en el orden real de la salvación y es, por tanto, caritas hacia Dios, la tematice el sujeto como tal o no"78. Rahner concibe, pues, la unidad entre el amor a Dios y al prójimo casi de igual forma a como ha concebido la unidad entre naturaleza y gracia. Así como no hay una naturaleza pura porque ya está siempre elevada por la gracia divina a existencial sobrenatural, de la misma manera cada acto de auténtico amor ya esıá elevado por la gracia divina en el orden de la salvación.

Como ya lo indicamos en el apartado sobre la filosofía de Rahner, este texto sobre la unidad del amor a Dios y del amor al prójimo marca una evolución importante en su pensamiento en la dirección de una teoría de la interpersonalidad. Ya no es el conocimiento de otra cosa sino "el tú personal y conocido la mediación del sujeto para con su estar-cabe-si'79. En otras palabras, el hombre logra la conciencia y la plenitud de sí mismo solamente en el encuentro y en la entrega a un otro. Rahner supera, así, el objetivismo de "Espíritu en el mundo" y de su pensamiento temprano: "EI acto humano fundamental es, pues, cuando sucede, positivamente, amor al prójimo en cuanto caritas, es decir amor al prójimo cuyo movimiento está orientado finalmente hacia el Dios de la vida eterna"80.

76. En Escritos de Teologia VI. Madrid, 1967, pp. 27I-292.

77. Ibid., p. 272.

78. Ibid., p. 277.

79. Ibid., p. 282.

80. Ibid., p. 283. 
Rahner no tuvo miedo de argumentar a partir de la experiencia humana del amor interpersonal, y -pensamos- este enraizamiento de la reflexión teológica en la expericncia humana explica en buena parte la gran repercusión de la teología de Rahner. He aquí un significativo texto suyo sobre el amor interpersonal:

En el amor por ejemplo, cuando un hombre debe decirse a sí mismo: yo mismo, tan limitado como soy, tan frágil y tan poco fiable como soy, no puedo ser causa bastante para que otra persona me ame incondicionalmente. Y yo misno sé con total certeza cuán disculible es la persona amada y, no obstante, experimento en mí, de forna incomprensible, una osadía que salta por encima de las limitaciones de la otra persona. En ambos casos, el amor es absoluto: se apoya y vive sobre un fundamento que no se halla tan sólo en los amantes, ni puede ser dirigido y dominado por ellos. Es ... incomprensible. Y esto es la experiencia de Dios ${ }^{81 .}$

Esta interpenetración de la experiencia de Dios y del amor el prójimo llevará también a un cambio inportante en la comprensión de la potentia oboedientialis: ésta ya no será concebida meramente como la absoluta, ilimitada transcendentalidad del espíritu para la gracia, sino como "la transcendentalidad hacia el tú que hay que amar y que es, por de pronto, el hombre-junto-anosolros" 82 .

Por último, estas reflexiones sofisticadas y hasta retorcidas desembocan en la tesis fundamental de la estricta identidad recíproca del amor a Dios y del amor al prójimo:

El amor al prójimo calegorial y explícito es el acto primario del amor a Dios que en el amor al próimo mienta siempre, aunque atemáticamente, a Dios en su transcendentalidad sobrenatural. El amor a Dios explícito está sustentado por esa apertura confiada y amorosa hacia la totalidad de la realidad que sucede en el amor al projimo. Radicalmente, con necesidad onlo-lógica y no meramente "moral" o psicológica, es verdad que quien no ama al hermano, a quien ve, no podrá tampoco amar a Dios, a quien no ve, y que a un Dios, a quien no ve, le podrá amar únicamente en cuanto que ama al hermano visible 83 .

Al final de su escrito sobre la unidad del amor a Dios y al projimo Rahner apunta a una fundamentación cristológica de dicha unidad, que tiene su fundamento en la humanidad de Jesús. El hombre Jesús es la mediación del amor a Dios. Se puede amar a Dios solamente en el seguimiento de Jesús. Se puede

81. En H. Vorgrimler, Ensender a Karl Rahner. Introducción a su vida y su penscimienso, Barcelona, 1988, p. 28.

82. "Sobre la unidad"..., p. 285.

83. Ibid., pp. 289 s. 
amar a Jesús solamente amando al prójimo y especialmente al pobre y marginado.

\subsubsection{Ellacuría: del amor al prójimo a la opción por los pobres}

Sin referirse explícitamente a Rahner. Ellacuría, de nuevo, hace suyo el axioma de la unidad del amor a Dios y del amor al prójimo: "El amor a Dios en los hombres y a los hombres en Dios es un elemento esencial y diferenciativo del cristianismo"84. Este axioma se interrelaciona con otro axioma fundamental de Ellacuría sobre la realización de la salvación cristiana en la historia: "Miente quien dice preocuparse por la salvación trans-histórica y no se preocupa por la salvación histórica"B5. Así como la salvación se realiza en la historia, de la misma manera el amor a Dios pasa por el amor al hombre y es imposible sin él. El amor cristiano tiene que verificarse en la historia a través su fuerza salvadora: "Sólo si el amor cristiano llega a mostrar en la historia su radicalidad transformadora, servirá de signo de la salvación que predica" 86.

Por ello Ellacuría previene contra el peligro de concehir ese amor a la manera idealista y ahistórica. El amor cristiano debe realizarse históricamente desde la situación concreta en la cual se encuentran los seres humanos. Esto signfica que si la siluación de la mayoría de los seres humanos en América Latina está marcada por la miseria y la opresión, el amor cristiano en América Latina y en todas partes donde reina la injusticia licne que historizarse en la lucha por la justicia. Así lo esencial del cristianismo es "el amor de Dios en el amor a los hombres, la justicia como lugar de realización del amor en un mundo de pecado"87.

Esta relación entre el amor a Dios y el amor al prójimo constituye también el paradigma de la unión entre fe y justicia. El amor del hombre representa lo que es la justicia y el amor de Dios representa lo que es la le. De ahí concluye Ellacuría que "la justicia cristiana es el lugar donde se realiza el amor de los hombres y allí donde se da muestra la presencia del amor de Dios tal como se ha revelado en Jesucristo" $\mathrm{BB}$.

Por últinı hay que concretar quién es el ser humano a quien se dirige el amor cristiano, y la respuesta la da la parábola del buen samaritano. "La parábola muestra que es el samaritano quien verdaderaınente aına a Dios porque ama y actúa en favor del necesitado, que es su prójimo porque está en situación de desamparo (el prójimo es entonces el desamparado o, visto desde el otro lado. sc

84. Conversión de la iglesia... p. 255.

85. Ibid.,p. 191.

86. Ibid., p. 256.

87. lbid., p. 209.

88. "Fe y justicin", p. 56. 
es prójimo precisamente respecto del oprimido"B9. Otro texto biblico clave para Ellacuría es la ya mencionada parábola del juicio final según Mateo 25 . Y así, habla del Tercer Mundo como "el lugar donde habitan los pobres de la tierra y, tras los pobres de la tierra, el escondido pobre de la historia, que ha prometido estar tras el hambriento, el sediento, el encarcelado, el oprimido..." 90 . La parcialidad del amor cristiano hacia los pobres tiene su ejemplo en Jesús: "Jesús amó a todos, pero se situó del lado del oprimido y desde allí luchó enérgicamente pero amorosamente contra los opresores"91. La lucha por la justicia es la forma histórica del amor cristiano.

Para Rahner, como para Ellacuría, la clave última de la unidad del amor a Dios y al projimo es la cristología, pero no una cristologla abstracta de sustancias y naturalezas, sino una cristología vinculada al Jesús histórico y al caminar como Jesús caminó. Dice Ellacuría: "Este caminar tiene una dimensión fundamental que es el amor al hombre y tiene las formas distintas del amor en que se desplegó toda la vida de Jesús"92. Es Cristo quien se hace presente en el prójimo, pero no de manera indiscriminada, sino preferencialmente en los pobres y los sufrientes. Por eso el amor cristiano tiene que concretarse e historizarse en la opción por los pobres y en la lucha por la justicia.

\section{La clave cristológica}

Todo lo que hemos dicho deja en claro que tanto la teología de Rahner como la de Ellacuría es una teología de la unidad que supera los dualismos excluyentes entre naturaleza y gracia, lo divino y lo humano, la historia del mundo y la historia de la salvación, el amor a Dios y el amor al prójimo, el reino de Dios y el orden temporal. Pero tampoco se trata de identidad, sino de una unidad diferenciada, y el paradigma para pensar esta forma de unidad es el dogma cristológico de Calcedonia. "Se ha de reconocer a uno solo y el mismo Cristo Hijo Señor unigénito en dos naturalezas, sin confusión. sin cambio, sin división, sin separación, en modo alguno borrada la diferencia de naluralezas por causa de la unión, sino conservando, más bien, cada naturaleza su propiedad y concurriendo en una sola persona y en una sola hypostasis, no partido y divido en dos personas, sino uno solo y el mismo Hijo unigénito"93.

La unidad cristológica de la naturaleza humana y la naturaleza divina es la clave última para concebir las correlaciones mencionadas antes. Y en la medida en quc el dogma cristológico aúna divinidad y humanidad de Jesucristo en una

89. Hid., p. 48.

90. Comversión de la iglesia.... p. 294.

91. Ibid., p. 203.

92. "Fe y justicia", p. 51 .

93. El Magisterio de la Iglesia, Barcelona, 1963, p. 57. 
unidad diferenciada, la teología tiene también que aunar el esfuerzo por una transformación de la historia con la confianza creyente en la acción gratuita de la gracia divina. A este tipo de unidad llamamos con José Ignacio González Faus el "principio calcedónico"94.

\subsection{Rahner: Jesucristo como principio de unidad}

Esta idea recorre el pensamiento de Rahner. Ya en su texto sobre "Historia del mundo e historia de la salvación" hace uso del dogma de Calcedonia para pensar la unidad diferenciada de la historia del mundo y la historia de la salvación: "Sólo en Jesucristo se alcanza la unidad absoluta e indisoluble entre lo divino y lo humano"95. Históricamente esta unidad se hace presente en Jesús, y así se llega a una interpretación cristocéntrica del mundo:

El mundo y su historia están proyectados de antemano sobre el Logos de Dios hecho carne. Porque Dios quiso declararse a sí mismo en su eterna palabra, porque es el amor, por eso es el mundo, y precisamente en su diferencia de naluraleza y gracia, y de historia de la salvación e historia profana. Esto significa, que esa diferencia está abarcada por Cristo y la autodeclaración absoluta de Dios que sucede en él96.

Hay, pues, unidad y diferencia o, mejor dicho unidad en diferencia de la historia del mundo y de la salvación.

También en el texto sobre la unidad del amor a Dios y del amor al prójimo Rahner insistió en la importancia sistemática de la cristología: "un anor al prójimo que alcanza su consumación esencial absoluta (de índole sobrenatural) incluyc también la cristología"97. Y ya hemos recordado y recalcado la importancia de la humanidad de Jesús en la mediación del amor de Dios.

En el artículo "cristianismo" de su Diccionario reológico Rahner insiste todavía más en la historicidad de la revelación cristiana en la persona de Jesús: "Un dato fundamental, indeducible, de ninguna manera explicable, del cristianismo es la persona de Jesús, en la que la revelación divina se hizo delínitivamente histórica"98. Y ahí está la raíz de la unidad fundamental de la historia. "En Jesucristo y en su gracia, el mundo se hace historia de Dios mismo. Lil división básica de la historia total en historia profana e historia de la salvación sólo puede entenderse a partir de una concepción cristocéntrica"99.

94. Cfr. La humanidad nueva, Santander, 1975. p. 579.

95. "Historia del mundo e historia de la salvación", en Escritos de Teología V. Madrid. 1964, p. 128.

96. Ibid., p. 133.

97. "Sobre la unidad"..., p. 290.

98. Diccionario reológico, p. 137.

99. Ibid., p. 300. 


\subsection{Ellacuría: la transcendencia histórica en Jesús}

Ignacio Ellacuría en su teología de la historia adopta plenamente el principio calcedónico para unificar la historia de la salvación y la salvación de la historia. Hemos recalcado que Ellacuría niega una duplicidad de la historia en el sentido de una historia profana, que se supone puramente natural, y una historia sagrada, que se supone puramente sobrenatural. Para superar ese dualismo y concebir la unidad de la historia, Ellacurfa remite directamente al dogma de Calcedonia. "En este punto, la doble naturaleza, humana y divina, de Jesús en la unidad profunda de una única realidad englobante de ambas, ofrece un modelo de interpretación"100.

Y también la relación entre transcendencia e historia es pensada por Ellacuría según el principio calcedónico. "La transcendencia (...) se presenta como histórica y la historia se presenta a su vez como transcendente por más que resulte difícil encontrar los conceptos adecuados para mantener esta indivisa unidad sin confusión"'10ı. Con esta unidad sin separación ni confusión también la salvación histórica del ser humano y la liberación cristiana entran en una relación esırecha. "La liberación cristiana es, a la par, salvación en la historia y más allá de la historia. (...) La historia y el más allá de la historia no se identifican, pero muluamente se potencian" 102

La conexión sistemática de la unidad de la historia con la cristología se expresa de lorma especial en lo que es el reino de Dios: "El Reino de Dios es, a una, la presencia activa de Dios en la historia y la presencia de la historia en Dios, la historización de Dios, que no tiene por qué sonar más escandalosamente que la encarnación de Dios, y la divinización de la historia"l03. Es, de nuevo, cl principio calcedónico lo que permite concebir de manera adecuada la relación entre mundo y reino de Dios:

Una cosa es que se dé sin más una conexión intrínseca entre el reino de este mundo y el reino de Dios, entre la historia de la salvación y la salvación en la historia, y otra que se dé sin más una identilicación entre ambos extremos. Aquí también el misterio de la persona de Jesús en Jos naluralezas distintas no confundidas ni mezcladas sino radicalmente unificadas en una transcendencia única, es una pauta cristológica de interpretación, a la que permanentemente habremos que recurrir 104.

El principio calcedónico permite también concebir la liberación como liberación integral, en lo que tanto ha insistido el magisterio de la Iglesia en sus

100. "Historicidad de la salvación", p. 22.

10I. Ibid., p. 9.

102. Conversión de la iglesia.... p. 245.

103. Ibid., p. 17.

104. Teologia políica. p. 34. 
críticas de la teología de la libcración. "Para que la liberación luera integral, se debía atender a lo personal y a lo estructural, a lo espiritual y a lo material, a lo inmanente y a lo trascendente. Todo ello, en una perfecta unidad que ni confunde ni separa, es muy propio de la vida religiosa y de la mejor tradición jesuílica"105. De nuevo, Ellacuría insiste en que no hay que separar la liberación histórica y la salvación cristiana, pero tampoco hay que conlundirlas. "Cuando se toma el término liberación integral como actualización histórica de la salvación cristiana, ella misma tiene esa doble vertiente de realización mundanal y de realización transcendente, donde aquella es la objetivación en cada caso limitada de lo que pretende ser ésta como una mayor presencia del Dios siempre mayor"106. El cristiano no es, pues, ciudadano de dos mundos:

El cristiano no es ciudadano de dos mundos, sino de un solo mundo, en el que históricamente ha aparecido el Reino de Dios. Por eso debe presentarse una cierta confluencia de lo que es la historia de la salvación y lo que es la salvación en la historia. Confluencia no significa identidad, pero excluye loda disociación 107 .

Concluyamos con esta precisión importantc. Tanto Rahner como Ellacuría insisten en la importancia de la humanidad de Jesús para la cristología. Así lo dice Ellacuría en sus tesis sobre la correlación entre transcendencia e historia. "El principio explicativo estaría últimamente en una cristología nueva, que no se redujese al plantemaniento de Calcedonia, sino que se refíriese a la esencial conexión del Jesús histórico con el Cristo de la fe, en lo que es la unidad principal de Jesu-Cristo"108. Es en el Jesús histórico donde aparece la suprema forma de la transcendencia histórica. Así, Jon Sobrino recalca "que Ellacuría no ignoró ni la historia ni la transcendencia, tampoco las separó ni las mezcló en honda fidelidad a Calcedonia, sino que reformuló la relación entre ambas como transcendencia en la historia, de modo que de esta forma la historia va dando más de sî'log.

105. "Pedro Arrupe, renovador de la vida religiosa", Revisfa Larinoamericana de Teología 22, 1991. p. 22.

106. "En torno al concepto y la idea de liberación", en Varios. Implicaciones sociales y políricas de la teolngia de la liberación, Madrid, 1989, p. 103.

107. Conversión de la iglesia..., p. 221.

108. Tesis 9.4.3.I.

109. J. Sobrino, "Ignacio Ellacuría, el hombre y el cristiano. "Bajar de la cruz al pueblo crucificado"'. en I. Ellacuría, J. Sobrino, R. Cardenal, Ignacio Ellacuría, el hombre, el pensador, el cristiano. Bilbao, 1994, p. 53. 